\title{
The supernumerary segment systems of Rumex acetosa
}

\author{
A. S. Wilby and \\ J. S. Parker
}

School of Biological Sciences, Queen Mary College, University of London, Mile End Road, London E1 4NS

The dioecious flowering plant Rumex acetosa is polymorphic for heterochromatic supernumerary segments carried on the short arms of chromosomes 1 and 6 in British populations. SS1 is found in the majority of populations but at a very low frequency, averaging only 4 per cent of chromosome 1 . There is no obvious pattern to this distribution. SS6 was found in half the populations examined, all from the warmer southern and western parts of Britain. Overall it accounts for 6 per cent of chromosome 6 and averages 12 per cent in polymorphic populations. In heterozygotes SS1 is transmitted through the egg at a frequency of 0.63 , a highly significant deviation from expectation. Pollen transmission shows a slight but nonsignificant deficit of SS1 chromosomes. Mendelian expectations were fulfilled for seven crosses involving SS6. One cross, however, showed a highly significant excess transmission through the pollen. It is argued that meiotic drive plays a role in the maintenance of the ubiquitous SS1 low-frequency polymorphism but not the SS6 polymorphism which shows clear environmental correlations.

\section{INTRODUCTION}

One of the causes of intraspecific variation in DNA amount is the presence or absence of blocks of chromatin distributed between individuals within populations in a polymorphic fashion. These supernumerary segment systems are particularly prevalent in Orthoptera and usually involve blocks of heterochromatin (John, 1981) although some euchromatic segments have been found (Camacho et al., 1984). No effects of these segments on the external phenotype have been demonstrated but a close relationship exists between the presence or absence of the segments and the distribution of chiasmata (John and King, 1985). It has been argued that this redistribution of chiasmata is of adaptive significance (John, 1981).

Supernumerary segments are not well known in other groups of organisms and in plants, which are generally more tolerant of chromosome imbalance than animals, segments have seldom been reported. A few are known in the cytologicallyamenable family Liliaceae. In Scilla autumnalis a large number of supernumerary segments has been found, all of them euchromatic and many reaching polymorphic proportions (Ainsworth et al., 1983). A heterochromatic segment has also been reported in Tulipa australis (Ruiz Rejon et al., 1985). The pattern of inheritance has been investigated in both these species. In an autotetraploid race of $S$. autumnalis a segment on the short arm of chromosome 1 was transmitted in excess through both the pollen and eggs (Ainsworth et al., 1983) while in Tulipa the segment was inherited in a normal Mendelian fashion.

In the dicotyledonous plant Rumex acetosa two polymorphic supernumerary segments, both heterochromatic, have been found in British populations (Wilby and Parker, in press). In this paper the frequency, distribution and inheritance of these supernumerary segments on chromosomes 1 and 6 is considered. The segments show contrasting distributions with that on chromosome 6 showing a clear geographical pattern while that on chromosome 1 is without any apparent ecological or geographical correlates. One of the segments shows enhanced inheritance through the egg and this meiotic drive may play a significant role in the maintenance of the polymorphism.

\section{MATERIALS AND METHODS}

Seed collections of 31 British populations of Rumex acetosa have been examined. In 28 
populations seed from 10 females was collected and two offspring from each female, one male and one female, were examined cytologically. Thus a population sample of 20 plants was achieved. In the three remaining populations a single offspring from each of 40 females was examined. In addition, mature plants from 9 populations have also been studied. Sample sizes varied from 29 to 44 plants. The locations are given in tables 1, 2 and 3 .

Mitotic chromosomes were examined in roottip squashes after pre-treatment with 0.05 per cent colchicine and fixation in $1: 3$ acetic-alcohol. Meiotic analysis was carried out on PMCs fixed in Carnoy and stained in 2 per cent acetocarmine.

\section{RESULTS}

Rumex acetosa is a dioecious species with welldifferentiated sex-chromosomes- $2 n=12+X X$ in females and $2 n=12+X Y 1 Y 2$ in males (Wilby and Parker, 1986). The $X$ is a large metacentric while the $Y$ s are slightly smaller but with variable centromeric locations. The six pairs of autosomes are acrocentric with arm-ratios greater than $1: 2$. The autosomes grade in size from pair 1 with the longest arm in the complement to pair 6 which is markedly smaller than the rest and less acrocentric. The short arms of pairs 1 and 6 are of equal length and are the largest amongst the autosomes. During prophase the only heterochromatic regions are the two Y-chromosomes of males which carry minute terminal euchromatic regions.

Two different supernumerary segments have been found in British populations of $R$. acetosa, terminal on the short arms of chromosomes 1 and 6 . The segments are heterochromatic and appear as knobs during prophase (figs 1-4). The segments can also be identified during interphase as small chromocentres (fig. 5); the nuclei of females are otherwise homogeneous but in males the $Y$ s are visible as massive linear or circular blocks.

\section{SUPERNUMERARY SEGMENT 1}

The supernumerary segment on the short arm of chromosome 1 (SS1) leads to an increase in length of $0.5 \mu \mathrm{m}$, about 14 per cent of the total (fig. 2). The segment increases the length of the short arm by about 55 per cent, giving an arm-ratio of $1: 2 \cdot 3$ rather than $1: 3 \cdot 5$. Only one variant has been
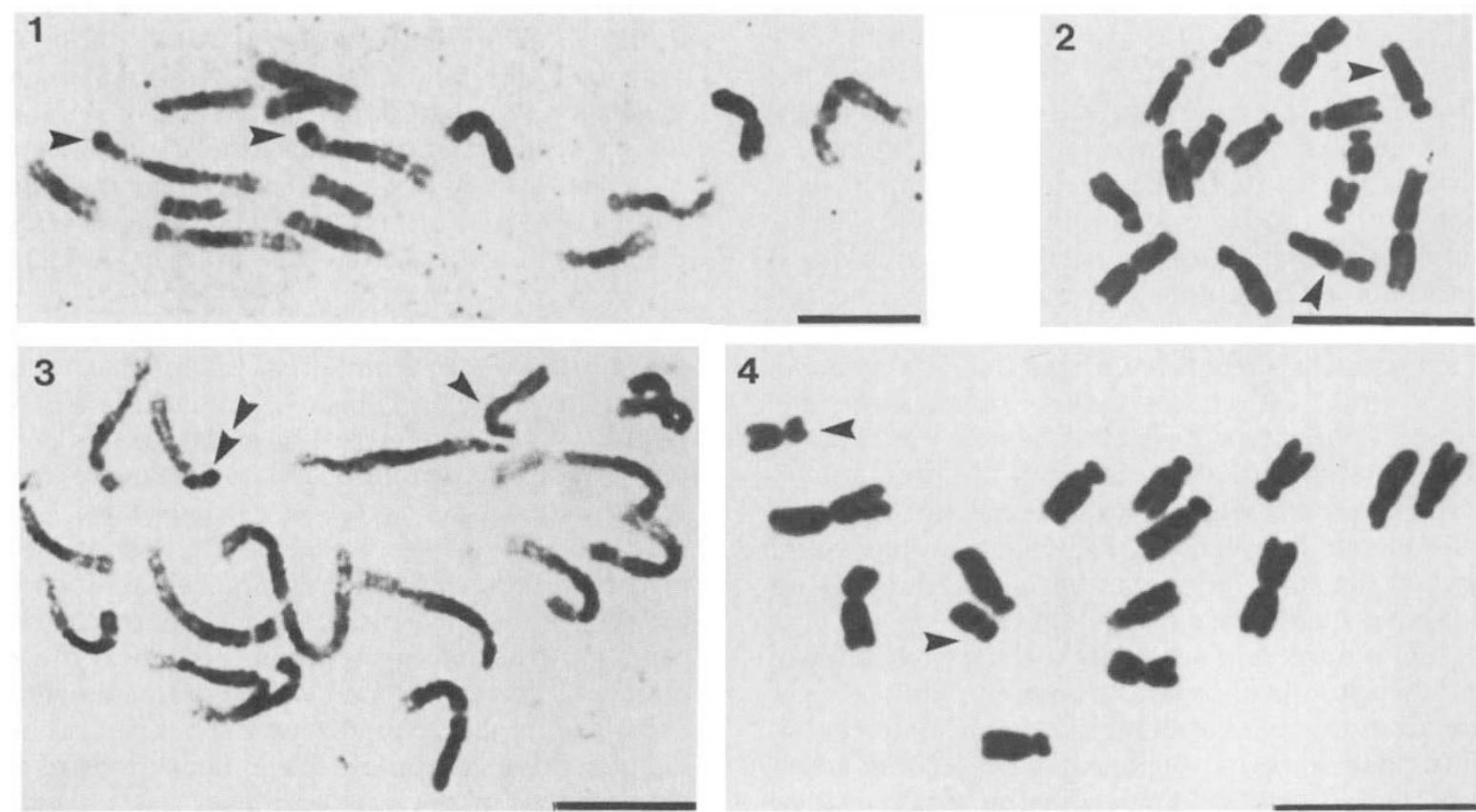

4
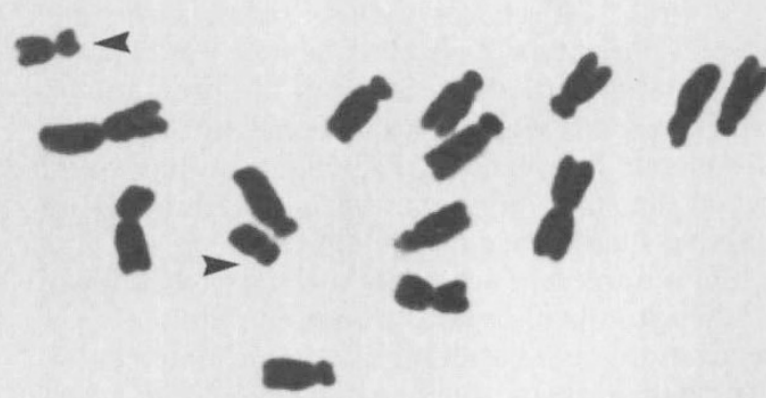

Figure 1 Mitotic prophase in Rumex acetosa o, $2 n=12+X Y 1 Y 2$, homozygous for supernumerary segments on the short arm of chromosome 1 (SS1). Segments are arrowed. Figure 2 Mitotic metaphase in Rumex acetosa male heterozygous for SS1. Pair 1 arrowed. Figure 3 Mitotic prophase in a male plant heterozygous for a supernumerary segment on chromosome 6 . The SS6 is indicated by a double arrow and the standard chromosome by a single arrow. Figure $4 \mathrm{C}$-metaphase in a male heterozygous for SS6. Pair 6 arrowed. Bar in all figures is $10 \mu \mathrm{m}$. 
found: a single plant from the Burnsall population contained a chromosome with about half the SS1 quantity of hetercchromatin, presumably as a result of deletion.

During meiosis the bivalent formed by pair 1 is identifiable at metaphase-1. In SS1 heterozygotes, the heteromorphism is usually evident despite the highly coiled nature of the bivalents (fig. 6). The short arm of chromosome 1 is often achiasmate in standard plants and very few heterozygotes have chiasmata adjacent to the segment. The segment may act, therefore, as a partial cross-over suppressor. There are no effects on chiasma formation in the long arm of chromosome 1 or the rest of the complement.

\section{Distribution}

Populations containing SS1 are scattered across the whole of Britain from the south coast of England to the Lowlands of Scotland, the most northerly so far studied (fig. 7). The segment is almost ubiquitous, since even with samples of only 20 or 40 plants it has been detected in 23 out of the 31 seed populations. There is no pattern to the distribution of SS1 and it is not limited to any particular geographic or climatic region; three of the five Welsh populations, however, do not carry the segment. The distribution pattern may represent a fixed polymorphism with the absences a reflection of sampling error.

Despite the common occurrence of SS1 it is usually at a low frequency within populations (tables 1-3). In the 28 seed populations (table 1) segment frequency in the 560 plants is only 0.043 and when monomorphic populations are excluded this only rises to 0.06 . Thus 13 of the 20 populations containing SS1 have only one or two heterozygotes in the 20-plant sample and only three populations with chromosome frequencies of $0 \cdot 1$ or higher have been recorded. At Tintagel, the population with the highest frequency $(0 \cdot 2)$, six heterozygotes and a single homozygote were found in the 20 plants. Overall only three SS1 homozygotes in the 560 plants were noted. A Hardy-Weinberg estimate, using the summed data, of $46 \cdot 1$ heterozygotes and 1 SS1 homozygote corresponds well with the observed 42 and 3 individuals. The segment is distributed between the sexes in proportion to the sex-ratio.

Three populations derived from the seed of 40 females-Hendra (Cornwall), Navestock Heath (Essex) and Torver (Cumbria)-gave similarly low SS1 frequencies (table 2).

These patterns of distribution and frequency are repeated in samples of mature plants (table 3 ). Eight of the nine populations contained SS1. Tintagel was also studied as a 20 -plant seed sample and Hendra, Navestock Heath and Torver in 40plant samples; the others were from previouslyunsampled areas. Five populations came from a small area of north Cornwall yet there is no consistency in chromosome frequency between these populations. Again the overall frequency of SS1 is low $(0.057)$ rising only to 0.064 in the eight polymorphic populations.

There is reasonable concordance between seed and mature plant frequencies. The Tintagel population is high in both, while Hendra and Navestock Heath are low in both; the Torver frequency is low in mature plants $(0.025)$ but much higher in the seed $(0 \cdot 1)$, although the presence of two SS1 homozygotes greatly weights this sample.

\section{Inheritance}

The inheritance of SS1 has been examined using chromosomes obtained from populations at Torver and Irton (Cumbria), Navestock Heath (Essex) and Hendra (Cornwall). In addition two crosses have been carried out using plants of the offspring generation carrying the Torver-derived SS1.
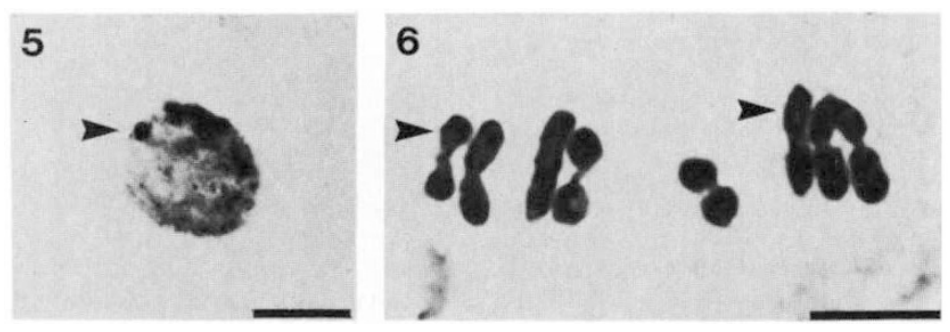

Figure 5 Interphase nucleus of male $R$. acetosa heterozygous for SS1. The SS1 chromocentre is arrowed. Figure 6 Metaphase-1 in PMC of $R$. acetosa, heterozygous for SS1 and SS6. Both heteromorphic bivalents arrowed. Bar in both figures is $10 \mu \mathrm{m}$. 


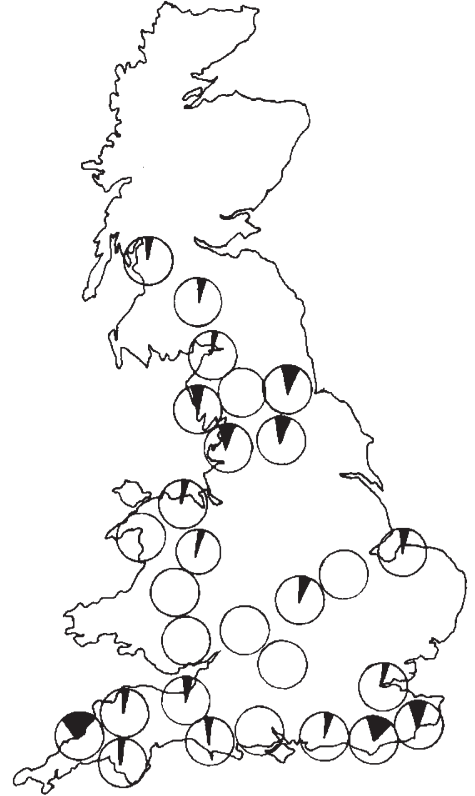

Figure 7 The distribution and frequency of SS1 in 28 British populations of $R$. acetosa. The frequencies are based on samples of 40 chromosomes from each population.

Four crosses of the backcross type SS1 heterozygote $q$ by basic homozygote $\delta$ have been carried out (table 4). All crosses showed excess transmission of the SS1 chromosome through the egg. Overall 88 heterozygotes out of 140 offspring (63 per cent) were recovered, a highly significant deviation from a $1: 1$ ratio $\left(\chi^{2}=9 \cdot 25 ; P<0 \cdot 01\right)$. Only one cross gives a significant deviation from equality but the homogeneity justifies pooling the data.

Through the pollen, by contrast, there is a deficit of segment-bearing chromosomes. Overall 79 out of the 182 offspring were heterozygous, a transmission frequency of 0.43 , but this is a nonsignificant deviation from the expected $1: 1$ ratio.

Pollen and egg fertilities are unaffected by the presence of supernumerary segments. Accumulation, therefore, does not depend on embryo lethality but must result from an excess of segmentcontaining female gametes.

\section{SUPERNUMERARY SEGMENT 6}

Chromosome 6 may also carry a heterochromatic segment terminal on the short arm (fig. 3). The segment (SS6) is about $0.4 \mu \mathrm{m}$ at mitotic metaphase leading to an increase of 19 per cent in chromosome length and 51 per cent in length of the short arm (fig. 4). Chromosome 6 is the smallest and also the least acrocentric member of the complement and the segment reduces the arm-ratio from $1: 2 \cdot 2$ to $1: 1 \cdot 5$. As with SS1, SS6 is identifiable as a chromocentre in interphase nuclei.

At metaphase- 1 of meiosis the bivalent formed by pair 6 is always identifiable because of its small size (fig. 6). SS6 heterozygotes do not form chiasmata in the segment-bearing arm. In basic homozygotes, however, this arm is seldom chiasmate so chiasma decline may not be of significance in the genetic system of this species.

\section{Distribution}

SS6, in contrast to SS1, has a clear pattern of distribution. In the 28 seed populations SS6 occurs in a broad belt across southern England, throughout Wales and into the lowlands of southern Scotland. It is absent both from the small, rather isolated populations of eastern England and the huge continuous populations of northern England (fig. 8; tables 1-3). Six populations from Cumbria, Lancashire and Yorkshire were monomorphic although the forty-female and mature plant samples from Torver (Cumbria) did

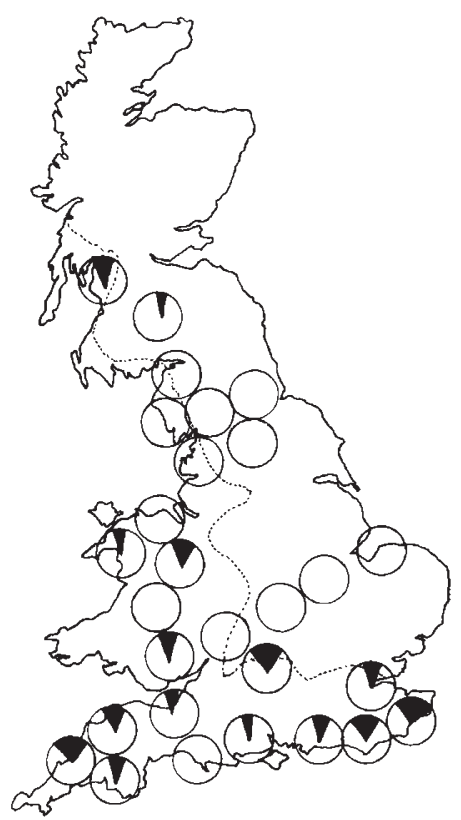

Figure 8 The distribution and frequency of SS6 in British populations, based on samples of 40 chromosomes. Indicated on the map is the $4.4^{\circ} \mathrm{C}$ January isotherm. Notice the absence of polymorphic populations from the colder eastern and northern areas. 
Table 1 The frequencies of supernumerary segments on chromosomes 1 (SS1) and 6 (SS6) in 28 populations of Rumex acetosa from Britain. Each sample of 20 individuals comprises one male and one female offspring from wild-collected seed samples of 10 females

\begin{tabular}{|c|c|c|c|c|c|c|c|c|c|}
\hline Population & Map ref & ++ & $\begin{array}{l}\mathrm{SS} 1 \\
+\mathrm{S}\end{array}$ & SS & Freq. & ++ & $\begin{array}{l}\text { SS6 } \\
+\mathrm{S}\end{array}$ & SS & Freq. \\
\hline Abington & NS930233 & 18 & 2 & - & 0.05 & 18 & 2 & - & 0.05 \\
\hline Bickton & SU153127 & 20 & - & - & - & 18 & 2 & - & 0.05 \\
\hline Bodfari & SJ091710 & 19 & 1 & - & 0.025 & 20 & - & - & - \\
\hline Bury Hill & TQ004121 & 18 & 2 & - & 0.05 & 15 & 5 & - & $0 \cdot 125$ \\
\hline Charminster & SY674944 & 19 & 1 & - & 0.025 & 20 & - & - & - \\
\hline Clipston & SP713821 & 18 & 2 & - & 0.05 & 20 & - & - & - \\
\hline Dacre & NY470257 & 18 & 2 & - & 0.05 & 20 & - & - & - \\
\hline Forton & SD504511 & 17 & 3 & - & 0.075 & 20 & - & - & - \\
\hline Hawes & SD862870 & 17 & 2 & 1 & $0 \cdot 1$ & 20 & - & - & - \\
\hline Heacham & TF697373 & 18 & 2 & - & 0.05 & 20 & - & - & - \\
\hline Penarth & SH605287 & 20 & - & - & - & 17 & 3 & - & 0.075 \\
\hline Postbridge & SX656796 & 19 & 1 & - & 0.025 & 16 & 4 & - & 0.1 \\
\hline Rhos-goch & SO021558 & 20 & - & - & - & 20 & - & - & - \\
\hline Rye Foreign & TQ900226 & 17 & 3 & - & 0.075 & 11 & 8 & 1 & 0.25 \\
\hline Tintagel & SX049885 & 13 & 6 & 1 & 0.2 & 11 & 9 & - & 0.225 \\
\hline Torrington & SS515192 & 19 & 1 & - & 0.025 & 14 & 6 & - & $0 \cdot 15$ \\
\hline Tubney Woods & SP451008 & 20 & - & - & - & 13 & 7 & - & 0.175 \\
\hline Vange & TQ715868 & 19 & 1 & - & 0.025 & 15 & 5 & - & 0.125 \\
\hline Wartling & TQ655085 & 14 & 6 & - & $0 \cdot 15$ & 12 & 8 & - & 0.2 \\
\hline West Buckland & ST155205 & 18 & 2 & - & 0.05 & 17 & 3 & - & 0.075 \\
\hline Willersey Hill & SP120386 & 20 & - & - & - & 20 & - & - & - \\
\hline Totals & & 515 & 42 & 3 & 0.043 & 488 & 68 & 4 & 0.068 \\
\hline
\end{tabular}

* One chromosome carries only part of the heterochromatin of SS1.

carry a low frequency of SS6. The distribution of SS6 may be temperature-related. Polymorphic populations are absent from areas where the average daily mean January temperature is less than $4.4^{\circ} \mathrm{C}$; that is eastern and northern England (fig. 8).

As well as a contrasting geographical distribution to SS1, SS6 has a distinctive occurrence between and within populations. SS6 was found in only 15 of the 28 seed populations. It occurs with a frequency of 0.068 but this rises to 0.127 in polymorphic populations: 10 of the 15 polymorphic populations have chromosome frequencies greater than $0 \cdot 1$, with a maximum of 0.25 at Rye Foreign, Sussex (cf. $3 / 20$ for SS1). The observed karyotype frequencies closely approximate to a Hardy-Weinberg equilibrium and again there is no difference in frequency between the sexes.

The populations of mature plants have similar SS1 frequencies to the seed samples. The frequency in polymorphic populations is 0.114 compared to 0.127 in seed and there is a close correlation

Table 2 The frequencies of SS1 and S6 in three large populations of $R$. acetosa. A single offspring was scored from each of forty females

\begin{tabular}{|c|c|c|c|c|c|c|c|c|c|}
\hline Population & Map ref. & ++ & $\begin{array}{l}\text { SS1 } \\
+1\end{array}$ & 11 & Freq. & ++ & $\begin{array}{l}\text { SS6 } \\
+6\end{array}$ & 66 & Freq. \\
\hline Hendra & SX139881 & 39 & 1 & - & 0.013 & 33 & 7 & - & 0.0875 \\
\hline Torver & SD277938 & 34 & 4 & 2 & $0 \cdot 1$ & 34 & 6 & - & 0.075 \\
\hline Totals & & 111 & 7 & 2 & & 101 & 18 & 1 & \\
\hline
\end{tabular}


Table 3 The frequencies of SS1 and SS6 in 9 populations of $R$. acetosa. The scores were obtained from mature plants

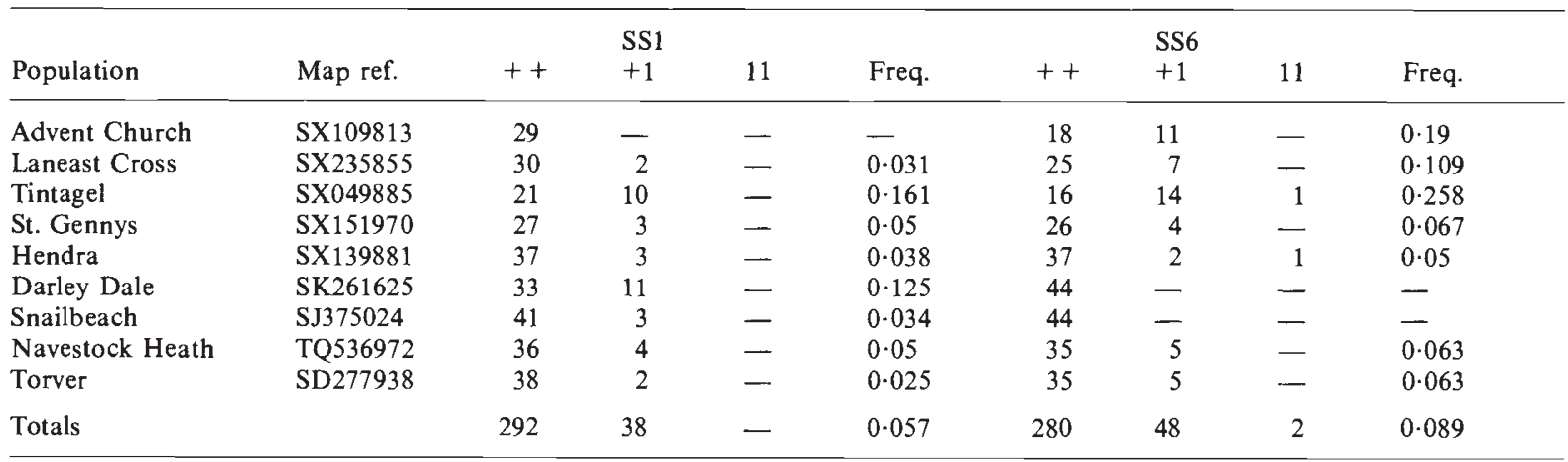

between seed and mature plant frequencies in the four populations screened at both stages of the life cycle (tables 1-3).

\section{Inheritance}

SS6 inheritance has been studied using chromosomes derived from Hendra, Navestock Heath, Torver and Tubney Wood. Seven backcrosses between heterozygotes and basic homozygotes, and a single cross between heterozygotes have been carried out (table 5).

When the SS6 heterozygote was used as egg parent ( 3 crosses) equal frequencies of basic homozygotes and heterozygotes were recovered $(56: 48)$. The four reciprocal crosses, however, gave conflicting results. Three showed a 1:1 ratio (34 homozygotes: 40 heterozygotes) while the fourth gave a highly significant excess of heterozygotes $\left(\chi^{2}=13 \cdot 7 ; \quad P<0.01\right)$. The heterozygote $\times$ heterozygote cross closely approximated a $1: 2: 1$ ratio (table 5).

Thus one chromosome, derived from the Hendra population, shows accumulation through the pollen. Interestingly the same segment chromosome was used on the egg side (cross 2) and gave an exact $1: 1$ (table 5). Further crosses will establish whether this is a persistent phenotype and whether accompanied by gametic or zygotic death. There is, however, no consistent involvement of meiotic drive or accumulation in the maintenance of this polymorphism.

\section{DISCUSSION}

Populations of Rumex acetosa in Britain are commonly polymorphic for heterochromatic supernumerary segments on the short arms of

Table 4 The pattern of inheritance of SS1 assessed from crosses between heterozygotes and basic homozygotes. The population from which the segment-bearing chromosome was derived is indicated

\begin{tabular}{|c|c|c|c|c|}
\hline \multirow{2}{*}{$\begin{array}{l}\text { Cross } \\
+19 x++\delta\end{array}$} & \multicolumn{2}{|c|}{ Offspring } & \multirow[b]{2}{*}{ Total } & \\
\hline & ++ & +1 & & \\
\hline 1. Navestock Heath & 15 & 19 & 34 & \\
\hline 2. Navestock Heath & 13 & 22 & 35 & \\
\hline 3. Hendra & 6 & 23 & 29 & $\chi^{2}=4.98 *$ \\
\hline 4. Torver & 18 & 24 & 42 & \\
\hline Totals & 52 & 88 & 140 & $\chi^{2}=9 \cdot 25^{* *}$ \\
\hline \multirow{2}{*}{$\begin{array}{l}\text { Cross } \\
++q x+1 \delta\end{array}$} & \multicolumn{2}{|c|}{ Offspring } & & \\
\hline & ++ & +1 & Total & \\
\hline 1. Navestock Heath & 24 & 13 & 37 & \\
\hline 2. Torver & 17 & 13 & 30 & \\
\hline 3. Torver & 21 & 14 & 35 & \\
\hline 4. Torver & 23 & 17 & 40 & \\
\hline 5. Irton & 18 & 22 & 40 & \\
\hline Totals & 103 & 79 & 182 & $\chi^{2}=3 \cdot 16$ n.s. \\
\hline
\end{tabular}


chromosomes 1 and 6. Samples from 37 different populations have been examined, 28 consisting of only 20 individuals. Despite these relatively small sample sizes, only 4 populations contained neither of the segments while 17 carried both. The supernumerary segment systems then are a standard feature of the genetic system of this species in Britain.

Supernumerary segments have been reported in $R$. acetosa from several other parts of the range of this extremely widespread species. The heterochromatic nature of the segments was first recognised by the Japanese authors Kurita and Kuroki (1971, 1975). Although it is not explicitly stated, it appears from their photographs that segments on chromosomes 5 and 6 were found. Although British populations of $R$. acetosa do not carry segments on chromosome 5 , they are common in the closely-related European montane species $R$. arifolius (Wilby and Parker, in preparation).

Segments, presumably heterochromatic, had previously been reported in Japanese populations by Ono (1935) and Yamamoto (1938). The data of Ono (1935) indicate a chromosome 6 segment which increases short arm length by 23 per cent, remarkably similar to the figure of 19 per cent for British plants. Segments have also been illustrated in plants from Poland (Gajewski et al., 1963) and Czechoslovakia (Vana, 1972). In none of these reports, however, has the nature of the chromosome variation been established and the Polish workers ascribe karyotypic heterogeneity to numerous inversions and interchanges. SS6 at least is distributed across the Old World range of the species and appears morphologically-constant.

In British populations SS1 and SS6 exhibit contrasting patterns of distribution and frequency. SS1 is widespread but at low frequency without any obvious environmental correlates while SS6 reaches reasonably high frequencies in populations from the south and west of England and in Wales. For SS6 then there may be a selective component in this distribution since it is virtually absent from areas where the mean January temperature is less than $4.4^{\circ} \mathrm{C}$.

The inheritance patterns of the segments are very distinctive. In SS1 there is drive through the egg with about 63 per cent of the gametes of heterozygotes carrying the segment. Accumulation appears to be a regular feature of the behaviour of this segment. There is no decline in fertility, thus this must result from biased gamete production, true meiotic drive. Perhaps the orientation of the heteromorphic bivalent in SS1 heterozygotes is such that the segment-bearing arm is more frequently directed towards the functional pole of the embryo sac. In Zea mays the neocentric activity of K10 leads to an enhanced recovery of the knobbed chromosome in the offspring (Rhoades, 1952). Heterochromatic SS1 may show similar neocentric activity during female meiosis although there is no evidence of this in PMCs.

In the reciprocal crosses there is a (nonsignificant) deficiency of heterozygotes amongst the offspring. Since meiosis in PMCs is normal and fertility approaches 100 per cent loss of segment chromosomes must occur between pollination and germination. Pollen-tube competition is a possible candidate since $\mathrm{X}$ and XY-bearing tubes compete actively in the styles of this species under conditions of high pollen density (Correns, 1928; Wilby and Parker, unpublished). With sparse pollination no competition occurs and a $1: 1$ ratio results. If this is parallelled by the segments then, in the wild, pollen transmission should be near equality. Drive then would be even more potent in maintaining the SS1 polymorphism.

In experiment SS1 inheritance shows an accumulation of about 3 per cent by combining drive and drag. In the absence of selection, even this low level of accumulation would rapidly lead to fixation. SS1 therefore may be slightly deleterious and is maintained, at a low level, by drive counteracting the tendency for segment elimination. The driving segment will carry the rest of chromosome 1 through to the next generation and should therefore distort genetic ratios of loci linked to the segment. With the low frequency of chiasmata in the segment-bearing arm and distal localisation of chiasmata the major portion of chromosome 1 should undergo segregation distortion.

SS6 has a different pattern of inheritance. Through the egg and in three of the four pollen-side backcrosses SS6 was inherited in a standard Mendelian fashion, while a $1: 2: 1$ was generated in an F2. In the remaining backcross, however, threequarters of the offspring were heterozygotes. This chromosome, from the Hendra population, was also used as an egg parent (cross 2) and gave a $1: 1$ ratio. There is no associated loss of pollen fertility but it is not yet known whether there is any zygotic lethality. Again, pollen-tube competition cannot be excluded. Tube competition, however, need not be associated with the segment itself: this may simply serve as a specific chromosome or centromere marker. Unlike SS1, it seems that meiotic drive is unlikely to play a major and consistent role in the maintenance of the SS6 polymorphism. 
Table 5 The pattern of inheritance of SS6. The population origin of the segment-bearing chromosome is given

\begin{tabular}{|c|c|c|c|c|c|}
\hline \multirow{2}{*}{$\begin{array}{l}\text { Cross } \\
+69 x++\delta\end{array}$} & \multicolumn{3}{|c|}{ Offspring } & \multirow[b]{2}{*}{ Total } & \\
\hline & ++ & +6 & & & \\
\hline 1. Hendra & 18 & 11 & & 29 & \\
\hline 2. Hendra & 21 & 19 & & 40 & \\
\hline 3. Tubney Woods & 17 & 18 & & 35 & \\
\hline Totals & 56 & 48 & & 104 & \\
\hline \multirow{2}{*}{$\begin{array}{l}\text { Cross } \\
++q x+60^{\circ}\end{array}$} & \multicolumn{3}{|c|}{ Offspring } & \multirow{2}{*}{\multicolumn{2}{|c|}{ Total }} \\
\hline & ++ & +6 & & & \\
\hline 1. Torver & 17 & 17 & & 34 & \\
\hline 2. Torver & 9 & 13 & & 22 & \\
\hline 3. Hendra & 9 & 33 & & 42 & $\chi^{2}=13 \cdot 7^{* *}$ \\
\hline 4. Tubney Woods & 8 & 10 & & 18 & \\
\hline Totals & 43 & 73 & & 116 & $\chi^{2}=7 \cdot 76^{*}$ \\
\hline \multirow{2}{*}{$\begin{array}{l}\text { Cross } \\
+69 x+6 \delta^{\circ}\end{array}$} & \multicolumn{2}{|c|}{ Offspring } & & & \\
\hline & ++ & +6 & 66 & Total & \\
\hline 1. Torver $\times$ Navestock & 6 & 22 & 9 & 37 & \\
\hline
\end{tabular}

Supernumerary segments are well known in some groups of organisms, most notably the Orthoptera (Hewitt, 1979; John, 1981; Camacho et al., 1984). Although many eu- and heterochromatic segments have been found no inheritance studies have been reported. Accumulation is shown by a euchromatic segment in a tetraploid race of $S$. autumnalis (Ainsworth et al., 1983) but, unlike $R$. acetosa, through both the pollen and the eggs. The only other segment which has been tested-in the plant Tulipa australis-was inherited in a standard Mendelian manner (Ruiz Rejon et al., 1985).

It is tempting to speculate whether accumulation mechanisms are more widespread than is generally assumed. Many of the reported cases are associated with massive depression of fertility usually by sperm death, as in Segregation Distorter in Drosophila (Hartl and Hiraizumi, 1976) and the t-haplotypes of mice (Silver, 1985). This is not the case with the segments in Rumex acetosa or Scilla autumnalis. Perhaps some of the supernumerary segment systems of the Orthoptera also show anomalous patterns of inheritance which may be significant in the maintenance of these commonlyencountered polymorphisms.

Acknowledgements A. S. Wilby is supported by an S.E.R.C. Research Studentship.

\section{REFERENCES}

AINSWORTH, C. C., PARKER, J. S. AND HORTON, D. 1983 Chromosome variation and evolution in Scilla autumnalis. Kew Chromosome Conference, II, 261-268.

CAMACHO, J. P. M., VISERAS, E., NAVAS, J. AND CABRERO, J. 1984. C-heterochromatin content of supernumerary chromosome segments of grasshoppers: detection of an euchromatic extra segment. Heredity, 53, 167-175.

CORRENS, C. 1928. Bestimmung, Vererbung und Verteilung des Geschlectes bei den hoheren Pflanzen. Handb. der Vererbungswiss., 2, 1-138.

GAJEWSKI, W., SWIETLINSKA, Z., AND ZUK, J. 1963. Relationship between biosystematics and formal taxonomy of the Rumex acetosa group. Regnum Veg., 16-24.

HARTL, D. AND HIRAIZUMI, Y. 1976. Segregation distortion. In Ashburner, M. and Novitski, E. (eds.) The genetics and biology of Drosophila, Academic Press, New York.

HEWITT, G. M. 1979. Grasshoppers and crickets. Animal Cytogenetics, vol. 3: Insecta 1 Orthoptera, Gebruder-Borntraeger, Berlin.

JOHN, B. 1981. Heterochromatin variation in natural populations. Chromosomes Today, 7, 128-137.

JOHN, B. AND KING, M. 1985. The inter-relationship between heterochromatin distribution and chiasma distribution. Genetica, 66, 183-194.

KURITA, M. AND KUROKI, Y. 1971. Chromocenter in Rumex acetosa nucleus. Bot. Mag. Tokyo, 84, 18-23.

KURITA, M. AND KUROKI, Y. 1975. Heterochromatic segment of Rumex acetosa autosome. Cytologia, 40, 237-242.

ONO, T. 1935. Chromosomen und sexualitat von Rumex acetosa. Sci. Rep. Tohuku Imp. Univ. IV, 10, 41-210.

RHOADES, M. 1952. Preferential segregation in maize. In Gowen, J. W. (ed.) Heterosis, lowa State College Press, Ames. 
RUIZ REJON, C. AND RUIZ REJON, M. 1985. Chromosomal polymorphism for a heterochromatic supernumerary segment in a natural population of Tulipa australis Link. (Liliaceae). Can. J. Genet Cytol., 27, 633-638.

Silver, L. M. 1985. Mouse t-haplotypes. Ann. Rev. Genet., 19, 179-208.

VANA, V. 1972. The localisation of heterochromatic segments in the chromosomes of Rumex acetosa. Preslia, 44, 316-326.
WILBY, A. S. AND PARKER, J. S. 1986. Continuous variation in Y-chromosome structure of Rumex acetosa. Heredity, 57, 247-254.

YAMAMOTO, Y. 1938. Karyogenetische Untersuchungen bei der Gattung Rumex. Mem. Coll. Agr, Kyoto Imp. Univ., 43, $1-59$. 